\title{
Neck movements in ankylosing spondylitis and their responses to physiotherapy
}

\author{
SUSAN L. O'DRISCOLL, ${ }^{1}$ M. I. V. JAYSON, ${ }^{1}$ AND H. BADDELEY ${ }^{2}$ \\ From the Department of Medicine, University of Bristol, and Royal National Hospital for Rheumatic Diseaseso \\ Bath $^{1}$; and Department of Radiodiagnosis, Bristol Royal Infirmary ${ }^{2}$
}

SUMMARY Cervical spine movements were compared in 35 patients with ankylosing spondylitis (AS) and matched controls. In AS there were limitations of all movements and particularly of later秽 flexion. These limitations could not be correlated with any particular features of AS except radion logical involvement of the lower apophyseal joints. In 25 patients there were significant improvements in all measurements after 3 weeks of intensive inpatient physiotherapy. After discharge the patients were encouraged to perform unsupervised physiotherapy and in 11 patients seen at 3 months the improvements in neck movements were either maintained or increased further. In contrast $n \hat{\&}$ changes in movements were found in 9 patients assessed 3 weeks and immediately before starting physiotherapy.

Limitation of cervical movements is a characteristic feature of ankylosing spondylitis (AS). However, we can find little objective data quantifying this. Although it is generally accepted that physiotherapy exercises aimed at improving spinal movements form an essential part of treatment, their value has not been adequately shown by clinical trials. In this study the ranges of cervical spine movements in patients with AS were compared with those of controls matched for age and sex. We used these measurements to evaluate the responses of AS necks to active physiotherapy.

\section{Clinical material}

We studied 35 consecutive patients with AS (criteria of Bennett and Wood, 1968), without selection according to cervical involvement. There were 25 males and 10 females aged between 24 and 59 years. They were all admitted for inpatient physiotherapy at the Royal National Hospital for Rheumatic Diseases, Bath, where it is the practice to treat ankylosing spondylitics for 3 weeks in classes, and give them intensive group physiotherapy with active mobilising exercises graded according to their degrees of disability. Patients were instructed to continue physiotherapy after discharge. The controls were healthy individuals without history of neck

Accepted for publication July 5, 1977

Correspondence to Professor M. I. V. Jayson, Department of Rheumatology, University of Manchester, Hope Hospital, Eccles Old Road, Salford, Manchester M6 8HD symptoms and were matched for age and sex witî the spondylitics.

In 25 patients we performed measurem gnt immediately before and after 3 weeks of phy $1 \infty^{\circ}$ therapy treatment without alteration of the regimen. In 9 we obtained a further set of meas ments 3 weeks before physiotherapy to provide $\frac{\text { ? }}{8}$ comparison with the effects of treatment. Finally repeated the readings in 11 patients 3 months afte discharge from hospital.

\section{Methods}

Each patient was assessed with a detailed clinical history and physical examination with particular. attention to the neck and the central nervous systen We used a spirit inclinometer (Back Pain Associa-tion) to measure cervical spine movements. The instrument was placed vertically and sagitally on the crown of the head with the subject in the neutra position. The subject was asked to flex and extend the neck and the degrees of flexion and extensiom were measured by the movements of the pointer. By rotating the inclinometer $90^{\circ}$, lateral flexion to the right and left were measured. The subject was then asked to lie flat and, with the inclinometer on tho forehead, rotation to the right and left was measure These measurements were all made by the sane observer.

To give a measure of the reliability of the measure ments in all directions three replications were obtained on successive days on each of 10 control 
The standard deviations and coefficient of variation between the replications were computed, and the distributions of these over the 10 patients examined.

We obtained radiographs of the cervical spine including lateral views in flexion and extension.

\section{Results}

Of the 35 patients, 23 were free of complications of AS, 10 had recurrent iritis, 1 aortic incompetence, and 1 Crohn's disease. No neurological abnormalities were found in any of the patients.

Table 1 shows the standard deviation and coefficient of variation for the replicated measurements and Table 2 gives the $95 \%$ limits for the values within which any replication would lie. The results show acceptable reproducibility of measurements performed by one observer. Movements of the cervical spine in all directions were compared with those of the matched controls (Fig.) We found that all measurements in the AS group were significantly diminished. In particular lateral flexion was most markedly reduced.

Table 1 Replicated measurements with inclinometer

\begin{tabular}{|c|c|c|c|c|}
\hline \multirow[t]{2}{*}{ Movement } & \multicolumn{2}{|c|}{$\begin{array}{l}\text { Standard deviation } \\
\text { in degrees }\end{array}$} & \multicolumn{2}{|c|}{$\begin{array}{l}\text { Coefficient of } \\
\text { variation }(\%)\end{array}$} \\
\hline & Mean & $S E$ & Mean & $S E$ \\
\hline $\begin{array}{l}\text { Lateral flexion } \\
\text { Rotation } \\
\text { Flexion } \\
\text { Extension }\end{array}$ & $\begin{array}{l}1.69 \\
1.61 \\
1.67 \\
1.41\end{array}$ & $\begin{array}{l}1.06 \\
0.90 \\
0.98 \\
0.95\end{array}$ & $\begin{array}{l}3 \cdot 45 \\
3 \cdot 52 \\
3 \cdot 56 \\
2 \cdot 79\end{array}$ & $\begin{array}{l}2 \cdot 25 \\
2 \cdot 30 \\
2 \cdot 04 \\
2 \cdot 36\end{array}$ \\
\hline
\end{tabular}

Table 2 Confidence limits

\begin{tabular}{ll}
\hline Movement & $\begin{array}{l}95 \% \text { limits about the mean } \\
\text { in degrees }\end{array}$ \\
\hline Lateral flexion & \pm 5.39 \\
Rotation & \pm 4.91 \\
Flexion & $\pm 5 \cdot 19$ \\
Extension & \pm 4.62
\end{tabular}
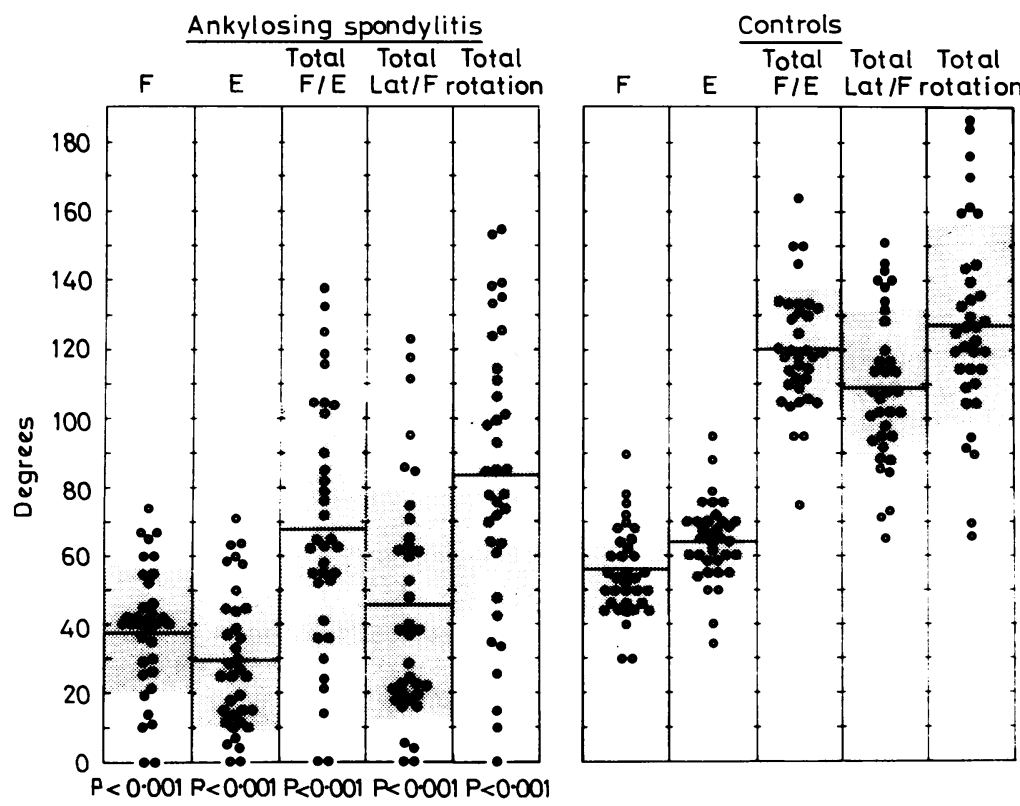

Fig. Movement of curvical spine in patients with ankylosing spondylitis compared with controls. $P$ values indicate the significance of the difference between the 2 groups. $F=$ flexion; $E=$ extension; Shaded area indicates $\pm S D$. neck. We could not correlate limitation of cervical movements with the length of history of AS, severity of neck symptoms, or the radiological findings apophyseal joints had the most severe restriction of lateral flexion.

We compared neck movements in 25 patients before and after 3 weeks of physiotherapy using paired Student's $t$ tests. Table 3 summarises the directions. In contrast there was little change in flexion/extension, lateral flexion, and rotation in the 9 patients assessed 3 weeks before and immediately efore starting inpatient physiotherapy (Table 4).

To determine whether the improvements with intensive inpatient physiotherapy would be maintained after discharge, we repeated measurements in patients 3 months after leaving hospital, again rotation continued to improve. 
Table 3 Cervical spine movements in ankylosing spondylitis before and after physiotherapy

\begin{tabular}{|c|c|c|c|}
\hline Movement (degrees) & Mean & $S E M$ & $P$ \\
\hline \multicolumn{4}{|l|}{ Flexion } \\
\hline Before physio & $28 \cdot 20$ & $2 \cdot 35$ & \\
\hline After physio & $39 \cdot 28$ & $2 \cdot 78$ & $<0.001$ \\
\hline \multicolumn{4}{|l|}{ Extension } \\
\hline Before physio & $23 \cdot 16$ & $2 \cdot 58$ & \\
\hline After physio & $30 \cdot 72$ & $3 \cdot 50$ & $<0.001$ \\
\hline \multicolumn{4}{|l|}{ Flexion/extension } \\
\hline Before physio & $51 \cdot 16$ & $4 \cdot 21$ & \\
\hline After physio & $70 \cdot 32$ & $5 \cdot 59$ & $<0.001$ \\
\hline \multicolumn{4}{|l|}{ Total lateral flexion } \\
\hline Before physio & $26 \cdot 44$ & 3.41 & \\
\hline After physio & $40 \cdot 48$ & $4 \cdot 59$ & $<0.001$ \\
\hline \multicolumn{4}{|l|}{ Total rotation } \\
\hline Before physio & $54 \cdot 48$ & 6.45 & \\
\hline After physio & $82 \cdot 20$ & $7 \cdot 75$ & $<0.001$ \\
\hline
\end{tabular}

Table 4 Cervical spine movements in ankylosing spondylitis 3 weeks before and immediately before physiotherapy

\begin{tabular}{lrrl}
\hline Movement (degrees) & Mean & SEM & $P$ \\
\hline Flexion/extension & & & \\
3 weeks before physio & 75.7 & 10.6 & \\
$\quad$ Immediately before physio & 81.4 & 8.3 & $>0.10$ \\
Total lateral flexion & & & \\
$\quad$ 3 weeks before physio & 47.22 & 28.08 & \\
$\quad$ Immediately before physio & 48.11 & 26.56 & $>0.10$ \\
Total rotation & 87.67 & 14.90 & \\
$\quad$ 3 weeks before physio & 103.22 & 14.39 & $<0.01$ \\
Immediately before physio & & & \\
\hline
\end{tabular}

Table 5 Cervical spine movements in ankylosing spondylitis on finishing physiotherapy and 3 months later

\begin{tabular}{lrcl}
\hline Movement (degrees) & Mean & SEM & $P$ \\
\hline Flexion/extension & & & \\
$\quad$ End of physio & 97.45 & 10.70 & \\
$\quad 3$ months later & 102.54 & 10.83 & $>0.10$ \\
Total lateral flexion & & & \\
$\quad$ End of physio & 63.36 & 9.65 & \\
$\quad 3$ months later & 76.82 & 8.74 & $<0.01$ \\
Total rotation & 106.64 & 17.17 & \\
$\quad$ End of physio & 136.91 & 11.94 & $<0.001$ \\
3 months later & & & \\
\hline
\end{tabular}

\section{Discussion}

The repeated measurements show that when performed by the same observer this technique for documenting cervical movements will provide acceptable reproducible results. Therefore it can be used to compare cervical movement between patients and controls and before and after treatment.

The ranges of neck movements in the controls were of a similar order to those found by Newell and Nicholls (1965) using a different measuring technique. Flexion and extension principally occur at the atlanto-occipital joints and rotation at the atlantoaxial joint. Lateral movements occur from C2-7.
Because of this, the limitation of movements of the neck provides some guide to the area of the cervie spine that is affected (Beetham et al., 1966).

As lateral flexion was most markedly reduced AS it is likely that the principal changes affected the mid and lower rather than the upper cervical spinge. The patients with most restriction of lateral flexign showed most lower apophyseal joint changess. However, in the remaining patients all movements the cervical spine were reduced with no correlation with symptoms or other radiological findings.

Both flexion and extension were reduced in The latter loss was more marked but this may have been due to a dorsal kyphosis tilting the negk forwards, so altering the neutral position. For tais reason flexion and extension were considered bợh separately and together. However, greater loss $\mathscr{Q}_{\mathrm{f}}$ cervical extension and flexion agrees with the observations of Sturrock et al. (1973), who examingd the whole spine in AS.

The intensive inpatient physiotherapy regimen consisted of graduated exercises directed at the whote spine, and sporting activities. This improved 迎l movements of the neck and these improvements we maintained for at least 3 months. Indeed, lateral flexion and extension continued to improve after patient returned home to do unsupervised phess therapy. The improvements during physiotheraigy were in marked contrast to the lack of change in क्षुg 3 weeks immediately preceding admission.

In addition to the objective benefits many patie described subjective improvements in, for examp, looking forwards, reversing cars, etc. All patiefts were encouraged to continue physiotherapy at homie after discharge and their willingness to do so toget laer with continued objective improvements of so parameters testify to its value.

We thank Drs P. Bacon, J. A. Cosh, and A. St:워. Dixon for allowing us to study their patients, Mr R. Harrison who was in charge of the physiotheray department, and Mrs E. Collins who performed statistical analyses.

\section{References}

Beetham, W. P., Polley, H. F., Slocomb, C. H., and Wea W. F. (1966). Physical Examination of the Joints, p. Saunders, Philadelphia.

Bennett, P. H., and Wood, P. H. N. (1968). (Edito N.) Population Studies of the Rheumatic Diseases, p. 4.53 . International Congress Series, No. 148. Excerpta Mediega,
Amsterdam.

Newell, D. J., and Nicholls, P. J. R. (1965). The accurac 50 of estimating neck movements. Annals of Physical Medicgoe
$8,120-124$.

Sturrock, R. D., Wojtulewski, J. A., and Hart, F. D. (1973 $)$. Spondylometry in a normal population and in ankylosing spondylitis. Rheumatology and Rehabilitation, 12, 135-1 